\title{
Diapause in Calanoid Copepods: within-clutch hatching patterns
}

\author{
Bart T. DE STASIO \\ Department of Biology, Lawrence University, Appleton, Wisconsin USA 54912 \\ e-mail address: Bart.T.Destasio@lawrence.edu
}

\begin{abstract}
Diapause is a major life history feature of many invertebrate organisms. Determining the phenology of diapause is critical for understanding survival and reproductive success of individuals as well as the long-term viability of many populations. The time spent in dormancy by individuals and variability among offspring in the duration of dormancy are two important aspects of invertebrate life histories. Some data are available, especially on duration of diapause, for plants and insects, but little information is available concerning variability among offspring in diapause traits. This is especially true for crustacean zooplankton, where essentially no information has been published on duration of diapause or variability among offspring in diapause timing or dynamics. Here I present data on the duration of diapause, and variability among offspring for diapause characteristics. The freshwater calanoid copepod Onychodiaptomus sanguineus, an obligately sexual species, was collected from Bullhead Pond, Rhode Island, U.S.A., and raised under conditions in the laboratory to induce production of diapausing eggs. One hundred clutches of these diapausing eggs (920 total eggs) were incubated for over two years in a full-factorial experiment testing the effects of temperature and photoperiod cycles on the hatching dynamics and duration of diapause. Overall hatching success was highest (approximately 86\%) for eggs exposed to simultaneous temperature and photoperiod cycles mimicking natural changes, and was lowest (approximately 20\%) when eggs were incubated at constant temperature $\left(4^{\circ} \mathrm{C}\right)$ and in constant dark conditions. The highest fraction of eggs hatched at approximately 550 days of age, but the age of eggs at hatching was highly variable among clutches. There was also large variability within clutches for hatching patterns, with some clutches containing eggs that all hatched synchronously and others in which eggs hatched more continuously throughout the experiment. Treatment conditions significantly affected within-clutch synchrony of hatching, as well as synchrony of the onset of hatching. These results of high within-clutch variability and differences among clutches in diapause dynamics have important implications for our understanding of reproductive success of individuals producing diapausing eggs, parent-offspring conflict, and the evolution of bet-hedging strategies in invertebrates.
\end{abstract}

Key words: diapause, calanoid, copepod, within-clutch, bet-hedging

\section{INTRODUCTION}

Diapause is a major life history feature of many invertebrate organisms (e.g. Hutchinson 1967; Tauber et al. 1986; Hairston \& Cáceres 1996; Fell 1998; Williams 1998). Having diapause as part of a life history is clearly advantageous under a number of circumstances, especially when environmental conditions periodically deteriorate for an organism. Although it is difficult to show that diapause is an adaptation to any specific environmental factor, it may provide an adaptive advantage for a number of reasons including avoiding predictably or unpredictably harsh conditions, as well as synchronizing life cycles and reproduction (Hairston 1998).

Determining the phenology of diapause is critical for understanding survival and reproductive success of individuals (e.g. Marcus 1979; Hairston and Munns 1984; De Stasio 1989; Hirche 1998). Two important aspects of invertebrate life histories are the time spent in dormancy by individuals and variability among offspring in the duration of dormancy. A fair amount of data are available on the duration of dormancy for a variety of crustaceans (e.g. Hairston \& Cáceres 1996), but little information is available concerning variability among offspring in diapause traits. A few studies have shown a significant maternal effect on diapausing eggs of Daphnia (e.g. De Meester \& De Jager 1993; De Meester et al. 1998) and on diapausing cysts of fairy shrimp (Van Dooren \& Brendonck 1998). To date there is no information for copepods on variability among siblings in hatching patterns or duration of diapause. However, these kinds of data are needed to understand the ecological and evolutionary implications of diapause as a bet-hedging strategy for organisms.

Here I present the first study to examine withinclutch variability in hatching patterns of diapausing eggs of a calanoid copepod, Onychodiaptomus sanguineus. Clutches of diapausing eggs of this species were reared and tested in the laboratory for the effects of temperature exposure and photoperiod cycles on hatching dynamics. The results indicate that both temperature and photoperiod are important external factors affecting termination of diapause, and that there is high within-clutch variability of hatching in this species.

\section{METHODS}

\subsection{Bullhead Pond}

Bullhead Pond (Rhode Island, U.S.A.) is a permanent, spring-fed body of water situated on a glacial end moraine. It has no inflowing or outflowing streams, and 
water depth fluctuates seasonally between 2.0 and 4.0 $\mathrm{m}$. It has a surface area of 2.3 ha and is located at $41^{\circ} 24^{\prime} \mathrm{N}$ and $71^{\circ} 36^{\prime} \mathrm{W}$. Complete ice cover occurs in January and February. The lake is mesotrophic with a typical maximum Chlorophyll- $a$ content of $15 \mathrm{mg} \mathrm{m}^{-3}$. Resident fish populations include sunfish (Lepomis macrochirus, L. gibbosus, and L. auritus), bullhead (Ictalurus sp.), chain pickerel (Esox niger), and smallmouth bass (Micropterus dolomieui) (De Stasio 1990). Seasonal planktivory by fish is an important factor affecting population dynamics, life histories, and timing of diapause egg production by the calanoid copepod Onychodiaptomus sanguineus (e.g. Hairston et al. 1983; Hairston 1987).

\subsection{Diapausing egg collection}

Female Onychodiaptomus sanguineus carrying eggs were collected from Bullhead Pond, RI, USA in late February and early March of 1988 and transported to the laboratory. Animals were maintained in the laboratory at $11^{\circ} \mathrm{C}$ and ambient light conditions. Offspring resulting from these subitaneous eggs also were raised at $11{ }^{\circ} \mathrm{C}$ and fed a mixture of laboratory cultures of the green algae Chlamydamonas and Scenedesmus. Males and females were allowed to mate haphazardly until females produced eggs. Under these conditions all females produced diapausing eggs.

On June 21, 1988 one hundred clutches of these newly produced diapausing eggs were placed into clear 20-ml glass vials with loosened caps, one clutch in each vial, in filtered water (GF/C Whatman Filter) from Bullhead Pond. All clutches used in this experiment were first clutches produced by each female.

\subsection{Incubation Treatments}

Vials were placed haphazardly into four treatment conditions where photoperiod and temperature were manipulated. Twenty-five clutches were incubated in each set of conditions. In Treatment 1 eggs were held at $4{ }^{\circ} \mathrm{C}$ in constant darkness (4C/Dark). Eggs in Treatment 2 were incubated at $4{ }^{\circ} \mathrm{C}$ but exposed to a changing photoperiod over the following two-year period (4C/Photo); daily light:dark (L:D) cycle was varied between 15:9 and 12:12 hours. Conditions for Treatment 3 included changing temperatures and constant dark conditions (Temp/Dark). Temperatures were varied between $4{ }^{\circ} \mathrm{C}$ and $15^{\circ} \mathrm{C}$. Finally, clutches in Treatment 4 were exposed to changing temperatures as well as changing photoperiods (Temp/Photo). Temperatures changed between $4{ }^{\circ} \mathrm{C}$ and $15^{\circ} \mathrm{C}$, and photoperiods alternated between L:D cycles of 15:9 and 12:12 hours. Light was supplied from cool white fluorescent bulbs, with a photon flux density during light periods of 15 umoles $\mathrm{s}^{-1} \mathrm{~m}^{-2}$.

\subsection{Data collection}

Vials were checked visually monthly during the first six months, and then once every six months for the re- maining 18 months of the experiment. Number of hatched nauplii, embryos with some eye development (i.e. eyed embryos), eggs without any noticeable development, and number of decayed eggs were recorded each time vials were checked. Empty eggshells (i.e. chorions) were also enumerated when present. Duration of diapause for individual eggs was estimated by determining time in the experiment when nauplii hatched. All eggs were produced one or two days before the experiment began. Date of hatching was determined to be the midpoint of the time interval between the date a nauplius or chorion was observed and the previous date when eggs were checked. The resulting estimate of diapause duration is only a rough approximation because some intervals were six months long. Hatching percentages were calculated after subtracting eggs that decayed during the experiment from the total starting number of eggs incubated.

\subsection{Statistical Analysis}

Data were assessed for departures from normality and for heteroscedasticity and were transformed accordingly. One-way analysis of variance (ANOVA) was performed to test for significant differences in hatching percentages among treatment conditions and duration of diapause among clutches and among treatment conditions. Data expressed as percentages were transformed with the arcsine-inverse procedure prior to analysis (Sokol \& Rohlf 1981). Statistical analyses were performed using SYSTAT (ver. 5.2).

\section{RESULTS}

A total of 920 diapausing eggs of Onychodiaptomus sanguineus were collected from laboratory-reared females. Average clutch size in the experiment was 9.4 eggs per clutch (standard error $=0.46$ ). There was no significant difference in clutch size among the treatment groups $\left(\mathrm{F}_{3,96}=0.543, \mathrm{P}=0.654\right)$. Overall survival of eggs in the experiment was $86 \%$, with decay and death of some eggs occurring due to build-up of excessive fungus or algae in the vials.

Hatching success was significantly affected by treatment conditions $\left(\mathrm{F}_{3,90}=7.69, \mathrm{P}=0.00012\right)$, with highest hatching occurring when eggs were subjected to both changing temperatures and changing photoperiod (Fig. 1). Exposure to a constant $4{ }^{\circ} \mathrm{C}$ temperature and dark conditions resulted in the lowest hatching success, with approximately $20 \%$ of eggs hatching over the twoyear period. Exposing diapausing eggs to a changing temperature cycle under dark conditions resulted in an increased hatching success $(67 \%)$ compared to incubation at a constant cold temperature and changing photoperiod (48\%).

\subsection{Within-clutch hatching patterns}

Aside from these clear patterns in treatment effects on overall hatching success, there were also clear differ- 


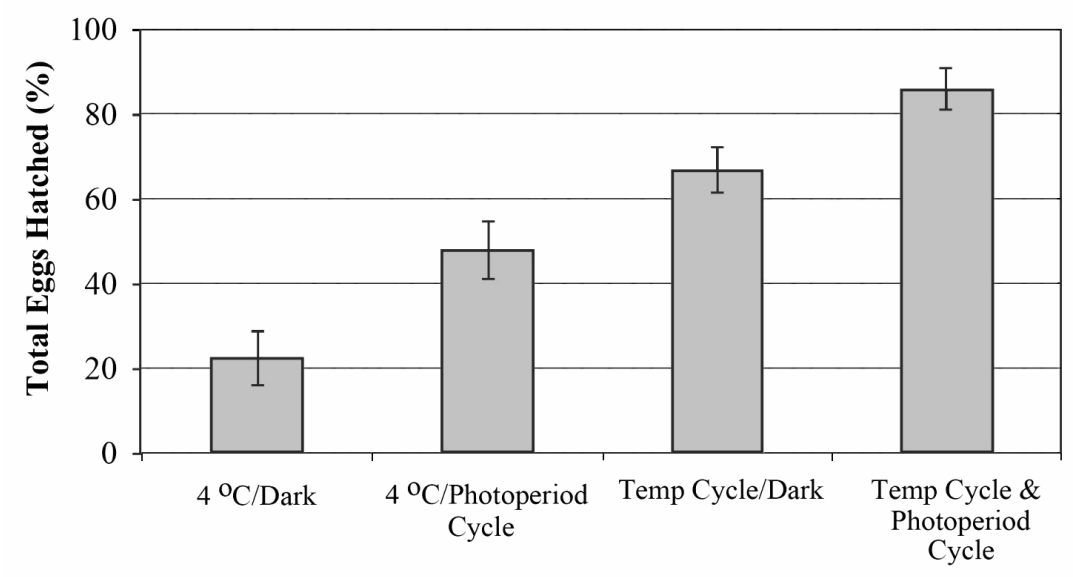

Fig. 1. Percentage of diapausing eggs of Onychodiaptomus sanguineus hatched in each of four experimental treatments testing the effects of temperature and photoperiod cycles on hatching success. Eggs were produced by lab-reared offspring of animals collected from Bullhead Pond, Rhode Island, USA. Details of treatment conditions are given in the Methods section.

ences between hatching patterns of eggs within a clutch. In all treatments there was a mixture of hatching patterns (Fig. 2). Many clutches contained eggs that hatched early and others that hatched later, resulting in a pattern of nearly continuous hatching over the 2 year period (e.g. Fig. 2d). In other clutches, hatching rate was more synchronous, with many eggs hatching at the same time and others in the same clutch either not hatching or breaking diapause together at a later date (i.e. March of 1989 in figure 2b and September of 1989 in figure 2c). This pattern produced pulses of hatching, especially in the Temp/Dark and 4C/Photo treatments.

First onset of hatching was generally earlier in the Temp/Photo and Temp/Dark treatments than in the other treatments (Fig. 2). By September of 1989 between 80 and $89 \%$ of clutches in either the Temp/Photo or Temp/Dark treatments had at least one egg hatch, while only $59 \%$ of clutches in the $4 \mathrm{C} /$ Photo and $40 \%$ in the $4 \mathrm{C} /$ Dark treatments had any hatching by that time.

\subsection{Duration of diapause}

Duration of diapause was significantly different among the four treatment conditions $\left(\mathrm{F}_{3,406}=3.284\right.$, $\mathrm{P}=0.021$ ), with an earlier peak in hatching occurring in the 4C/Dark treatment conditions (Fig. 3). Patterns of diapasuse duration were fairly consistent among the other three treatment conditions. In all treatments except the $4 \mathrm{C} /$ Dark treatment, the greatest percentage of eggs broke diapause at an age of 551 days, while hatching peaked at 374 days of age for eggs in the 4C/Dark treatment. Hatching first increased noticeably in all treatments starting at an age of 202 days and continued until the end of the experiment when eggs were at least 687 days old.

In each of the treatment conditions, there was also a significant difference among clutches in duration of diapause. This is clearly evident in figure 2, where in each treatment diapausing eggs in some clutches all hatched together either early in the experiment or late in the experiment, while in other clutches the eggs hatched more consistently throughout the two year period. The most significant difference among clutches occurred in the Temp/Dark treatment $\left(\mathrm{F}_{24,115}=3.261, \mathrm{P}=0.000012\right)$, but all other treatment conditions also showed significant differences among clutches in duration of diapause (4/Dark: $\mathrm{F}_{14,31}=2.153, \mathrm{P}=0.037$; Temp/Photo: $\mathrm{F}_{22,144}=$ 1.777, $\mathrm{P}=0.024$; 4/Photo: $\mathrm{F}_{19,50}=2.055, \mathrm{P}=0.022$ ).

\section{DISCUSSION}

The hatching success of diapausing eggs produced by Onychodiaptomus sanguineus in this experiment was significantly affected by both temperature and photoperiod cycles. Greatest hatching success occurred when eggs were exposed to a combination of temperature and photoperiod cycles, each occurring at times similar to natural changes in Bullhead Pond, RI, U.S.A. These results are consistent with the conclusions of many field investigations that demonstrate the importance of photoperiod and temperature as external factors affecting the release from diapause by both freshwater and marine crustaceans (e.g. Stross 1966; Marcus 1980; Pfrender \& Deng 1998). However, diapausing eggs did hatch during this experiment even when they were incubated continuously at $4{ }^{\circ} \mathrm{C}$ and in constant dark conditions (Fig. 1 ), indicating that some eggs will terminate diapause in the absence of external cues. Other studies have also shown that individuals will terminate diapause without any obvious external cues, usually resulting in a rather synchronous pattern of breaking diapause (e.g. Hirche 1983; Elgmork 1973; Williams-Howze \& Coull 1992; Alekseev 1998; Elgmork \& Lie 1998).

Within-clutch patterns of hatching were highly variable in all treatments, with significant differences among clutches in hatching timing (Fig. 2). Most clutches contained eggs that hatched at a variety of ages, suggesting that individual differences exist among eggs 
A.

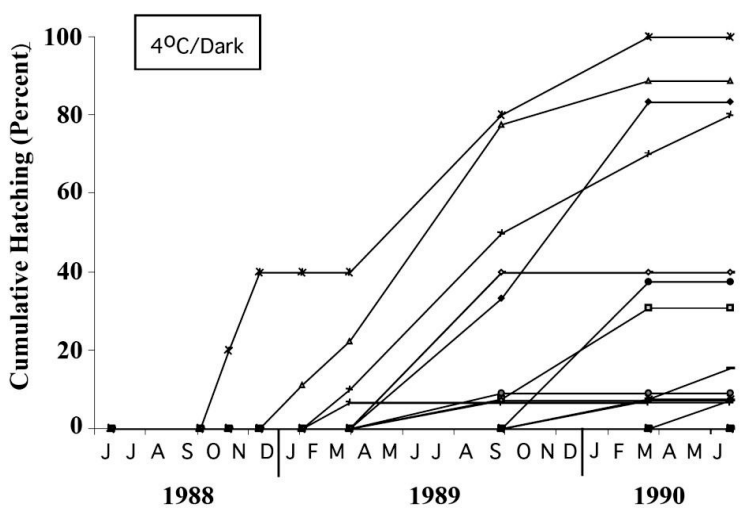

C.

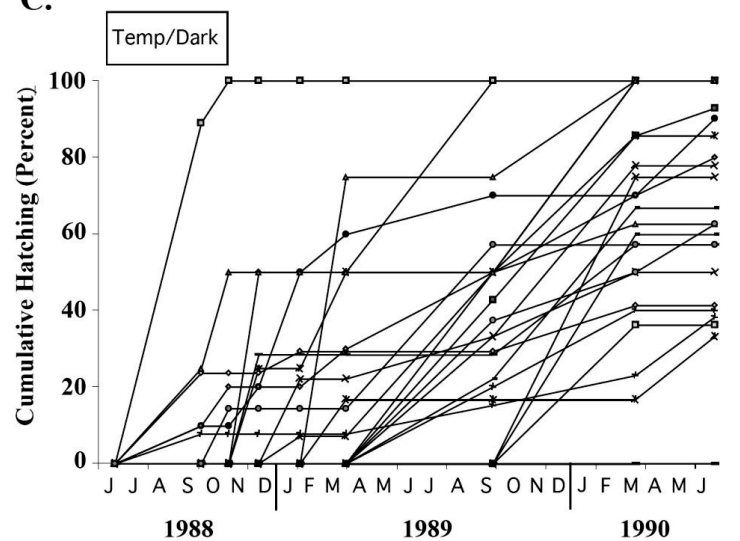

B.

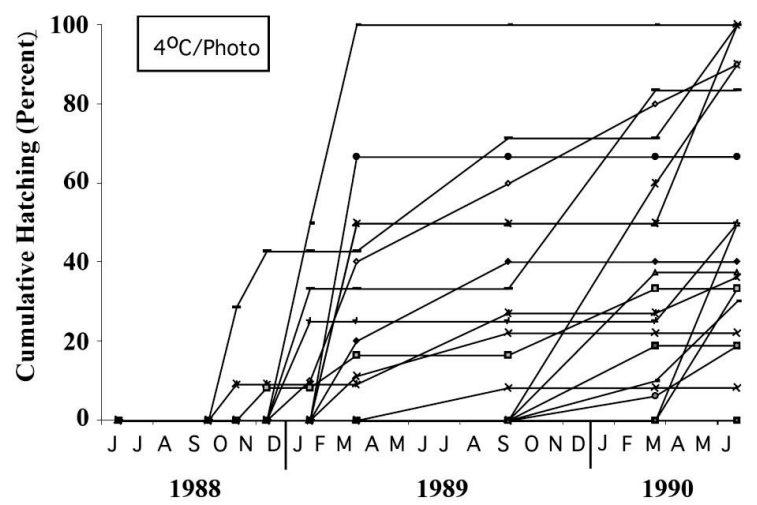

D.

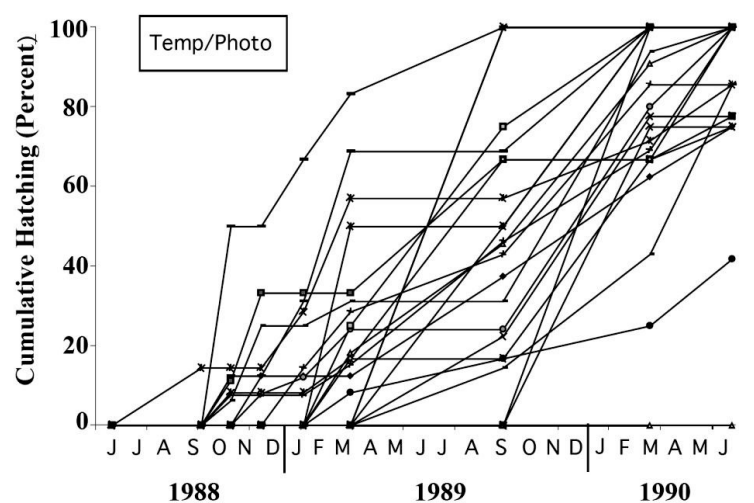

Fig. 2. Cumulative hatching dynamics of clutches of diapausing eggs of Onychodiaptomus sanguineus incubated for two years under A) constant $4{ }^{\circ} \mathrm{C}$ and dark conditions, B) constant $4{ }^{\circ} \mathrm{C}$ and alternating photoperiod conditions, C) alternating temperatures and constant dark, and D) alternating temperatures and photoperiods conditions combined. Each line represents the cumulative percentage of eggs within a single clutch that hatched by a given date.

within a clutch in either sensitivity to external cues to break diapause, or in internal timing mechanisms maintaining a diapause condition. To date, there appears to have been no other study of within-clutch hatching patterns of diapausing eggs of calanoid copepods. This is most likely because most studies have been conducted on field-collected eggs or based on sampling of emergence from sediments (Johnson 1967; Marcus 1987; De Stasio 1989, 1990; Taylor et al. 1990; Hairston et al. 2000). The study by Rossi et al. (1998) examining diapause phenology of Mixodiaptomus kupelwieseri tested clutches of diapausing eggs under wet and dry conditions, but results based on within-clutch patterns were not reported.

The results of high within-clutch variability in hatching patterns of $O$. sanguineus diapausing eggs stand in contrast to the few studies on other organisms examining maternal effects on hatching patterns. For instance, De Meester et al. (1998) found an important maternal effect on hatching of Daphnia magna diapausing eggs, and De Meester \& De Jager (1993) also found family-dependent effects on hatching rates of this same species. Similarly, Van Dooren \& Brendonck
(1998) found a significant maternal effect related to age of the mother on hatching success of cysts of the fairy shrimp Branchipodopsis wolfi. Based on all these results it is clear that there are differences in hatching patterns of diapausing eggs produced by the same mother when we compare the results for calanoid copepods with other groups like Daphnia and fairy shrimp. There is a clear need to investigate whether this difference holds for other species and populations of freshwater copepods.

Despite the high within-clutch variability of hatching observed in this experiment, the overall timing of emergence from diapause was fairly synchronous in each of the treatments (Fig. 3). While some eggs hatched as early as 4 months after being produced, the majority of diapausing eggs were approximately 1.5 years old when they hatched. The experimental conditions employed here did not exactly mimic the changes in temperature and photoperiod occurring in Bullhead Pond, so comparison between these results and field patterns should be viewed cautiously. However, it is intriguing to note that the age at which most eggs hatched in the laboratory resulted in them emerging at approximately the same time of year as $O$. sanguineus nauplii 


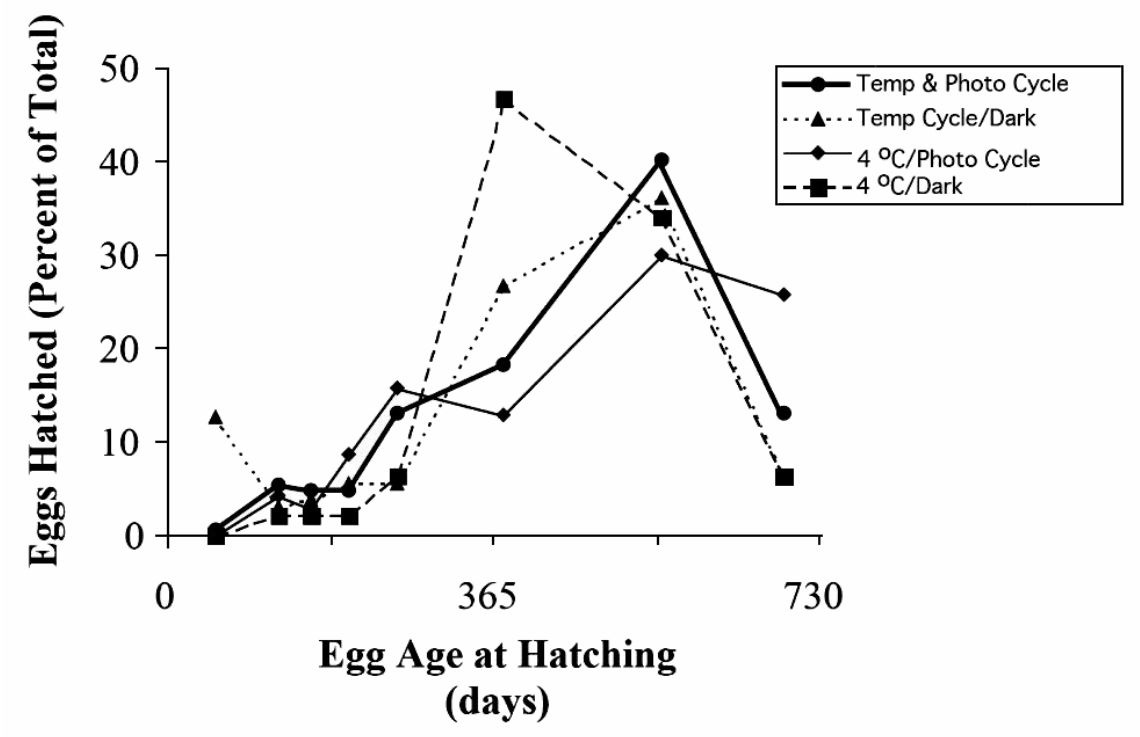

Fig. 3. Duration of diapause for eggs of Onychodiaptomus sanguineus incubated under four experimental conditions. Percentage of eggs that hatched during a given time interval is plotted against the average age of the eggs, separated by treatment exposure.

typically emerge in Bullhead Pond, primarily between November and March (De Stasio 1989). The fact that the main period of hatching of eggs provided with no external cues (i.e. in the 4C/Dark treatment) was earlier than in each of the other treatments may support the hypothesis that external cues play an important role in determining the timing of termination of diapause. Further careful experimentation to address this question is needed to reach any firm conclusions.

High within-clutch variability of hatching can have evolutionary significance considering the importance of long-term diapause to microevolution of freshwater zooplankton (Hairston \& Walton 1986; Hairston \& De Stasio 1988; Ellner et al. 1999). Results shown above (Fig. 2) clearly demonstrate that an individual mother produces eggs in a single clutch with a wide variety of diapause durations. This pattern results in her offspring potentially emerging into multiple environmental conditions, spreading out her investment in the future. This form of risk-spreading is in contrast to risk-spreading by producing eggs that will enter dormancy and avoid conditions that are currently poor but that will all emerge together some time in the future when conditions improve. The latter type of bet-hedging can be evolutionarily advantageous if hatching reliably occurs when conditions are improved and if hatching timing is a heritable trait. It seems likely that hatching timing may be heritable given that the timing of the onset of diapause in $O$. sanguineus has been shown to be highly heritable (Hairston \& Walton 1986; Hairston \& Dillon 1990). If hatching traits are heritable, then the variable patterns exhibited by siblings within a clutch may suggest that eggs can not reliably predict when conditions have improved in the environment. This speculation calls for more detailed experiments. Clearly, further studies of within-clutch patterns of termination of dia- pause for copepods would help further our understanding of the evolutionary importance of diapause in the life history of aquatic invertebrates in general.

\section{CONCLUSIONS}

Hatching patterns of diapausing eggs of Onychodiaptomus sanguineus have the potential to significantly affect the population dynamics and evolutionary ecology of this freshwater calanoid copepod. Assessing the relative importance of external cues compared to internal mechanisms in determining the hatching success and timing of termination of diapause is a critical need in order to further our understanding of invertebrate diapause.

Temperature exposure and photoperiod both had significant effects on hatching success and timing of hatching. However, there were also significant differences in within-clutch hatching patterns, even in the constant cold and dark treatment, indicating that internal mechanisms may also be important. Additional experiments should be performed to examine this aspect of the life history of this and other related species. The wide variety of hatching patterns also suggests that a highly diversified bet-hedging strategy may have evolved in this species.

\section{ACKNOWLEDGMENTS}

I thank N. Hairston, Jr., T. Dillon, and the University of Wisconsin Trout Lake Limnology Laboratory for laboratory support and assistance. Assistance with computer work and statistical analysis were kindly provided by A. Siebert and D. Lajus. N. Hairston, B. Rence, and E. De Stasio provided helpful discussions of the data. E. De Stasio also provided constructive criticisms of this manuscript. This research was supported by the 
Theodore Roosevelt Memorial Fund of the American Museum of Natural History, a Grant-in-Aide of Research from Sigma Xi, and by Lawrence University.

\section{REFERENCES}

Alekseev, V.R. 1998. Biochemical and physiological characteristics of crustaceans in diapause: The internal mechanism of reactivation. Arch. Hydrobiol. Spec. Issues Advanc. Limnol., 52: 463-476.

De Meester, L. \& H. De Jager. 1993. Hatching of Daphnia sexual eggs. II. The effect of age and a second stimulus. Freshwat. Biol., 30: 227-233.

De Meester, L., C. Cousyn, \& J. Vanoverbeke. 1998. Chemical interactions, maternal effects and the hatching of Daphnia diapausing eggs. Arch. Hydrobiol. Spec. Issues Advanc. Limnol., 52: 263-272.

De Stasio, B.T., Jr. 1989. The seed bank of a freshwater crustacean: copepodology for the plant ecologist. Ecology, 70:1377-1389.

De Stasio, B.T., Jr. 1990. The role of dormancy and emergence patterns in the dynamics of a freshwater zooplankton community. Limnol. Oceanogr., 35: 1079-1090.

Elgmork, K. 1973. Bottom resting stages of the planktonic copepod Cyclops scutifer Sars. Verh. int. Ver. Limnol., 18: 1474-1478.

Elgmork, K. \& S. Lie. 1998. Diapause in the life cycle of Cyclops scutifer (Copepoda) in a meromictic lake and the problem of termination by an internal clock. Arch. Hydrobiol. Spec. Issues Advanc. Limnol., 52: 371-381.

Ellner, S.P., N.G. Hairston, C.M. Kearns \& D. Babaï. 1999. The roles of fluctuating selection and long-term diapause in microevolution of diapause timing in a freshwater copepod. Evolution, 53: 111-122.

Fell, P.E. 1998. Ecology and physiology of dormancy in sponges. Arch. Hydrobiol. Spec. Issues Advanc. Limnol., 52:71-84.

Hairston, N.G., Jr. 1987. Diapause as a predator-avoidance adaptation. In: W. C. Kerfoot \& A. Sih (Eds), Predation: direct and indirect impacts on aquatic communities. University of New England Press, Hanover, NH: 281-290.

Hairston, N.G., Jr. 1998. Time travelers: What's timely in diapause research? Arch. Hydrobiol. Spec. Issues Advanc. Limnol., 52: 1-15.

Hairston, N.G., Jr. \& T.A. Dillon. 1990. Fluctuating selection and response in a population of freshwater copepods. Evolution, 44: 1796-1805.

Hairston, N.G., Jr. \& W.E. Walton. 1986. Rapid evolution of a life history trait. Proc. Natl. Acad. Sci. USA, 83: 48314833.

Hairston, N.G., Jr. \& B.T. De Stasio. 1988. Rate of evolution slowed by a dormant propagule pool. Nature, 336: 239242.

Hairston, N.G., Jr. \& C.E. Cáceres. 1996. Distribution of crustacean diapause: micro- and macroevolutionary pattern and process. Hydrobiologia, 320: 27-44.

Hairston, N.G., Jr. \& W.R. Munns, Jr. 1984. The timing of copepod diapause as an evolutionarily stable strategy. $\mathrm{Am}$. Nat., 123: 733-751.
Hairston, N.G., Jr., W.E. Walton \& K.T. Li. 1983. The causes and consequences of sex-specific mortality in a freshwater copepod. Limnol. Oceanogr., 28: 935-947.

Hairston, N.G., Jr., A.-M. Hansen \& W.R. Schaffner. 2000. The effect of diapause emergence on the seasonal dynamics of a zooplankton assemblage. Freshwat. Biol., 45: 133145.

Hirche, H.-J. 1983. Overwintering of Calanus finmarchicus and Calanus helgolandicus. Mar. Ecol. Prog. Ser., 11: 281-290.

Hirche, H.-J. 1998. Dormancy in three Calanus species (C. finmarchicus, C. glacialis and C. hyperboreus) from the North Atlantic. Arch. Hydrobiol. Spec. Issues Advanc. Limnol., 52: 359-369.

Hutchinson, G.E. 1967. A treatise on limnology. 2. J. Wiley \& Sons, New York: $660 \mathrm{pp}$.

Johnson, M.W. 1967. Some observations on the hatching of Tortanus discaudatus eggs subjected to low temperatures. Limnol. Oceanogr., 12: 405-410.

Marcus, N. 1979. On the population biology and nature of diapause of Labidocera aestiva (Copepoda: Calanoida). Biol. Bull., 157: 297-305.

Marcus, N. 1980. Photoperiodic control of diapause in the marine calanoid copepod Labidocera aestiva. Biol. Bull., 158: 311-318.

Marcus, N. 1987. Differences in the duration of egg diapause of Labidocera aestiva (Copepoda: Calanoida) from the Woods Hole, Massachusetts, region. Biol. Bull., 173: 169177.

Pfrender, M.E. \& H.-W. Deng. 1998. Environmental and genetic control of diapause termination in Daphnia. Arch. Hydrobiol. Spec. Issues Advanc. Limnol., 52:237-251.

Rossi, V.L. Montesanto \& P. Menozzi. 1998. Deposition season and hatching patterns of resting eggs in Mixodiaptomus kupelwieseri (Crustacea: Copepoda). Arch. Hydrobiol. Spec. Issues Advanc. Limnol., 52: 207-218.

Sokol, R.R. \& F.J. Rohlf. 1981. Biometry, 2nd edit., W.H. Freeman, New York, NY.

Stross, R.G. 1966. Light and temperature requirements for diapause development and release in Daphnia. Ecology, 47: 368-374.

Tauber, M.J., Tauber, C.A. \& S. Masaki. 1986. Seasonal adaptations of insects. Oxford University Press, Oxford: 411 pp.

Taylor, B.E., G.A. Wyngaard \& D.L. Mahoney. 1990. Hatching of Diaptomus stagnalis eggs from a temporary pond after a prolonged dry period. Arch. Hydrobiol., 117: 271278.

Van Dooren, T. \& L. Brendonck. 1998. The hatching pattern of Branchiopodopsis wolfi (Crustacea: Anostraca): Phenotypic plasticity, additive genetic and maternal effects. Arch. Hydrobiol. Spec. Issues Advanc. Limnol., 52: 219227.

Williams, D.D. 1998. The role of dormancy in the evolution and structure of temporary water invertebrate communities. Arch. Hydrobiol. Spec. Issues Advanc. Limnol., 52: 109-124.

Williams-Howze, J. \& B.C. Coull. 1992. Are temperature and photoperiod necessary cues for encystment in the marine benthic harpacticoid copepod Heterpsyllus nunni Coull? Biol. Bull., 182: 109-116. 